\title{
Review of Icing Effects on Wind Turbine in Cold Regions
}

\author{
Faizan Afzal, Muhammad S.Virk \\ Institute of Industrial Technology, University of Troms $\varnothing$, Narvik, Norway
}

\begin{abstract}
This paper describes a brief overview of main issues related to atmospheric ice accretion on wind turbines installed in cold climate region. Icing has significant effects on wind turbine performance particularly from aerodynamic and structural integrity perspective, as ice accumulates mainly on the leading edge of the blades that change its aerodynamic profile shape and effects its structural dynamics due to added mass effects of ice. This research aims to provide an overview and develop further understanding of the effects of atmospheric ice accretion on wind turbine blades. One of the operational challenges of the wind turbine blade operation in icing condition is also to overcome the process of ice shedding, which may happen due to vibrations or bending of the blades. Ice shedding is dangerous phenomenon, hazardous for equipment and personnel in the immediate area.
\end{abstract}

\section{Introduction}

Energy concerns are becoming more crucial and the world is struggling to find cleaner sources of energy. Wind is a renewable source of energy that is being used quite extensively nowadays, as the abundance of wind resources allows for the increase in production of renewable energy in the world. Wind energy is expanding significantly every year. Most of these investments are towards the northern Europe and the Arctic areas as shown in Figure 1. The cold climate effects the dynamical behavior of wind turbines in various ways and poses a serious challenge to the wind energy industry. An important factor is the location of wind park sites to gain maximum efficiency. There are not many issues regarding installation of wind turbine system in warm regions, but when it comes to cold climate various parameters need to be considered in terms of design and safety.

Icing has been recognized as hindrance in proper utilization of good wind resources of cold regions, as when the temperature lowers in winter seasons ice accretion can occur on wind turbine blades, which effects the efficiency of power output and sometimes its effects can be hazardous for the whole system. In cold climate regions when temperature drop below $0^{\circ} \mathrm{C}$, wind turbines may be exposed to heavy atmospheric conditions causing icing during winter operations. In these atmospheric conditions clouds or super cooled fog can emerge at lower elevations with a strong temperature inversion and these kind of condition may last for days or even weeks. Ice accretion not only affects the efficiency of wind turbine blades but also the structural behavior, aerodynamic performance and the fatigue life of the wind turbine blades. Ice accretion on blades results in power loss, changing blade aerodynamic characteristics and can cause instrument or controller errors on wind turbines. The amount of wind power loss depends on the amount of ice accumulation on the blades, blade design and turbine control.

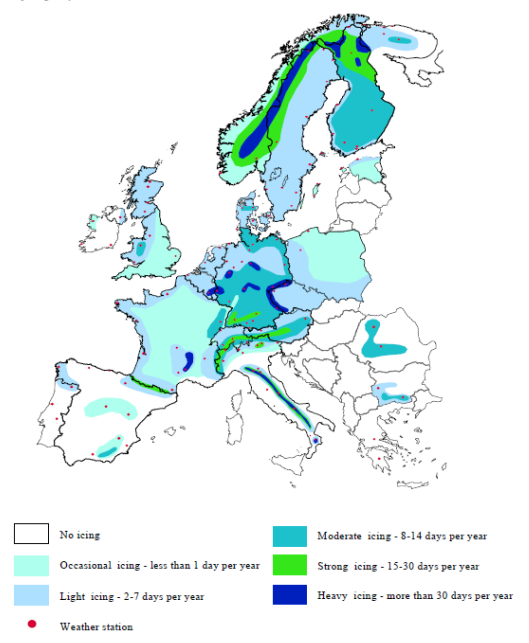

Fig. 1. Icing map of Europe 1.

The process of icing involves water droplets to be cooled below the freezing temperature $\left(0^{\circ} \mathrm{C}\right)$ and they will freeze upon the impact with the structure. Ice accretion along wind turbine blade can be of different types ranging from wet to dry ice as described in Table I.

Table 1. Types of Ice [2]

\begin{tabular}{|l|l|l|l|l|}
\hline \multirow{2}{*}{$\begin{array}{l}\text { Type of } \\
\text { ice }\end{array}$} & $\begin{array}{l}\text { Density } \\
\left(\mathbf{k g} / \mathbf{m}^{\mathbf{3}}\right)\end{array}$ & $\begin{array}{l}\text { Adhesion and } \\
\text { cohesion }\end{array}$ & \multicolumn{2}{|l|}{ General Appearance } \\
\cline { 5 - 5 } & & Colour & Shape \\
\hline Glaze & 900 & Strong & transparent & Icicles \\
\hline $\begin{array}{l}\text { Wet } \\
\text { Snow }\end{array}$ & \multirow{3}{*}{$\begin{array}{l}300 \text { to } \\
600\end{array}$} & Weak(forming) & White & Icicles \\
\cline { 3 - 3 } & & Strong(frozen) & & \\
\hline
\end{tabular}




\begin{tabular}{|l|l|l|l|l|}
\hline $\begin{array}{l}\text { Hard } \\
\text { rime }\end{array}$ & $\begin{array}{l}600 \text { to } \\
900\end{array}$ & Strong & Opaque & $\begin{array}{l}\text { Pointing } \\
\text { windward }\end{array}$ \\
\hline $\begin{array}{l}\text { Soft } \\
\text { rime }\end{array}$ & $\begin{array}{l}200 \text { to } \\
600\end{array}$ & $\begin{array}{l}\text { Low to } \\
\text { medium }\end{array}$ & white & Point windward \\
\hline
\end{tabular}

Wind power is proportional to air density accordingly the power output increases at low temperatures and the higher energy output has sparked an increasing interest in sites at both higher altitude and latitude. Despite of many difficulties, there exists increasing interest in cold climate wind turbines operation.

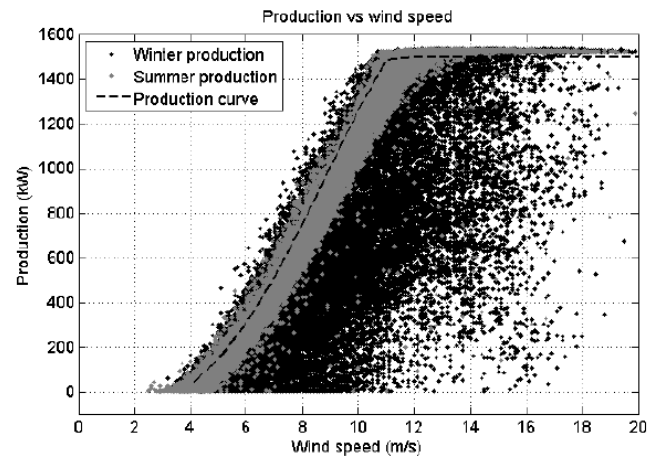

Fig.2. Power curve in summer and winter operating conditions $I$ [3].

The icing on wind turbine blades effects its dynamic behavior. Ice accretion on the blades is different on different blades designs, and it causes imbalance during rotation. Accreted ice effects on mechanical behavior have received widespread attention. Severe weather conditions possess a challenge to the wind power industry since icing of the wind turbine blades and sensors may induce losses in production, increase in the fatigue of the different components that leads to serious structural integrity issues and hence reducing the expected economical outcome. 1

\section{Ice Detection}

Ice accretion on wind turbines can be detected either by direct or indirect methods. Direct methods involves some property change (mass, reflective properties, electrical or thermal conductivity, dielectric coefficient and inductance) caused by the ice accretion of ice. The indirect methods are based upon detecting the weather conditions that lead to icing such as humidity and temperature or detecting the effects of icing such as reduction in power production. The common methods for detection of ice on wind turbines are listed in Table II.

Table 2. Methods of Ice Detection [3].

\begin{tabular}{|l|l|l|}
\hline No & Direct Detection & Indirect Detection \\
\hline 1 & $\begin{array}{l}\text { Damping of ultrasonic } \\
\text { waves in wire }\end{array}$ & Dew point and temperature \\
\hline 2 & $\begin{array}{l}\text { Damping of ultrasonic } \\
\text { waves on the wing surface }\end{array}$ & $\begin{array}{l}\text { Actual power output vs predicted } \\
\text { from wind speed }\end{array}$ \\
\hline 3 & Inductance change & $\begin{array}{l}\text { Anemometers with and without } \\
\text { heating }\end{array}$ \\
\hline 4 & Impedance change & Frequency of generated noise \\
\hline
\end{tabular}

\begin{tabular}{|l|l|l|}
\hline 5 & Capacitance change & $\begin{array}{l}\text { Change in blade resonant } \\
\text { frequency }\end{array}$ \\
\hline 6 & Temperature rise with heat & - \\
\hline
\end{tabular}

The best way to detect icing on the blades is by mounting the sensors on the blades of wind turbine as close to the tip as possible. This is due to three reasons:

- The rate of ice accretion is directly related to the relative velocity of the supercooled water droplets.

- Blade tip experience icing due to low clouds even though the nacelle is ice free.

- Outer ends of the blades sweep a larger volume and collect water or ice from the entire volume.

\section{Structural behaviour of iced wind turbine}

There is a clear trend in the wind energy industry towards scaling up the turbine size to improve the energy capture by a single machine and thereby bring down the cost of power generation by economies-of-scale factors. For cold climate operations, large turbines are often facing a harsh and complex service environment and may be damaged by many load and environmental factors such as fatigue, lightening, fire, air turbulence, moisture, and particularly icing. Ice accretion on wind turbines has been considered a hazard to its structural integrity. Ice accretion is not uniform along the wind turbine blade length and ice loads show a rapid increase at the tip and little ice can be observed near the root sections of the blade. The weight of accreted ice in some severe weather situations can be as high as $50 \%$ of the blade weight, which indicates the seriousness of icing on failure risk of the wind turbine structure. Low temperatures and icing affect the materials used in the fabrication of wind turbines, usually adversely. Additional vibrational stress can be introduced due to the mass imbalance in icing conditions. Large hard chunks of ice dislodged from the blade may come into direct contact with various parts of the wind turbine structure causing barely visible impact damage. All of these may trigger premature micro cracking and delamination in the wind turbine material. These micro cracks reduce both the stiffness and the impermeability of the material, which can accelerate the deterioration process causing structural failure of the wind turbine in cold climates. Crack formation due to cold climate and delamination crack growth under fatigue is one of the main factors affecting structural integrity of wind turbines in icing conditions. Considering the long design life ( $>20$ years) and the dynamic nature of the wind turbine blade loading, detailed fatigue failure analysis is required at critical locations of the wind turbine blade to ensure efficient and safe wind turbine operations in icing conditions. Techniques to improve the through-thickness strength of the composite materials are being developed to prolong the fatigue life of the structure.

Wind turbine blade has the same effects as that of the structural beam. Ice accumulation on the wind turbine blades is not the same across the blade length, as it depends on many parameters and it increases with the 
duration of icing event. Ice on the blade causes more loads and vibrations in the turbine. In order to certify wind turbines and their components for cold climate operation, Germanischer Lloyd proposed guidelines that defines the maximum ice mass distribution on the blade to calculate loads acting on the turbine in various design load cases. In the GL guidelines, ice mass density linearly increases from zero at the blade root to a value of $\mu_{\mathrm{E}}$ until the half blade length; mass density is constant towards the tip as shown in the Figure 3.3The value of $\mu_{\mathrm{E}}$ ice calculated as follows

$$
\mu_{E}=\rho_{E} k * c_{\min }\left(c_{\max }+c_{\min }\right)
$$

$\rho_{\mathrm{E}}$ is the density $\left(700 \mathrm{~kg} / \mathrm{m}^{3}\right)$, $\mathrm{k}=0.00675+0.3 e^{\left(-0.32 \frac{R}{R_{1}}\right)}, \mathrm{R}$ is the rotor radius in meter unit, $\mathrm{R}_{1}=1 \mathrm{~m}$, and $\mathrm{c}_{\max }, \mathrm{c}_{\min }$ are the maximum and minimum chord lengths of the blade in meter unit respectively [3].
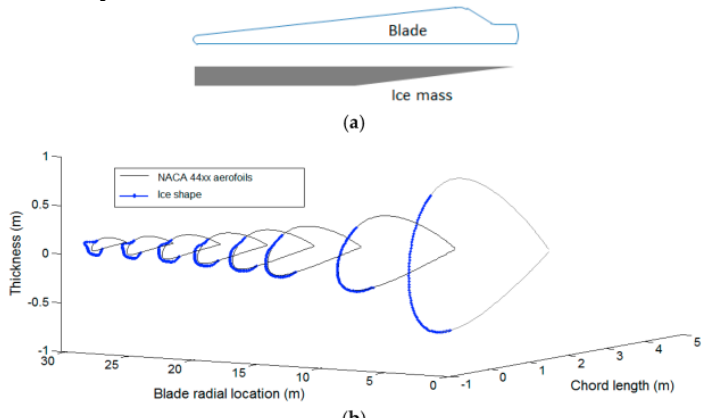

(b)

Fig.3. Ice mass distribution on turbine blade [3].

The operation of a wind turbine with an imbalance caused by icing experiences an increase in the loads on all turbine components. The extreme loads are treated in the design level, the fatigue loads will shorten the lifetime for the components. The details of these effects are illustrated in the WECO (Wind Energy Production in Cold Climates) project. They found the following

- Additional ice masses will cause higher deterministic loads

- Asymmetric masses will cause imbalance

- Ice accretion will increase the excitation of edgewise vibrations

- Resonance may occur due to the changed natural frequencies of the blades, particularly for smaller turbines and lightweight rotor blades

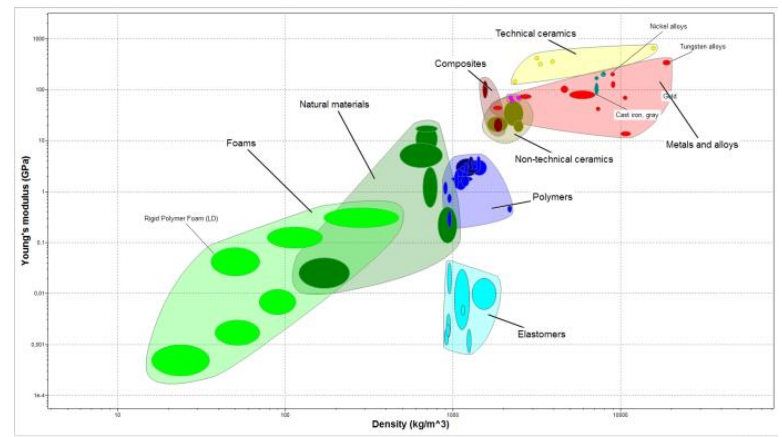

Fig.4. Material selection in wind turbine blades [4].
Significant advancement in technologies and modifications in wind turbine blades designs over the years have been achieved. Comparison of materials is done using CES EDUPack. It describes all the properties of materials. As shown in Figure 4. Graph shows the comparison of Young's modulus with density. It only shows the groups of materials involved. It is evident that we can discard Foams, Natural materials, polymers and elastomers. Technical ceramics are too brittle for the selection of wind turbine blades.

Figure 5 describes the comparison of material properties from density ranges from 500 to $3000\left(\mathrm{~kg} / \mathrm{m}^{3}\right)$ with young's modulus. Turbine blades are made from aluminum or some carbon-based compound (usually carbon fiber).

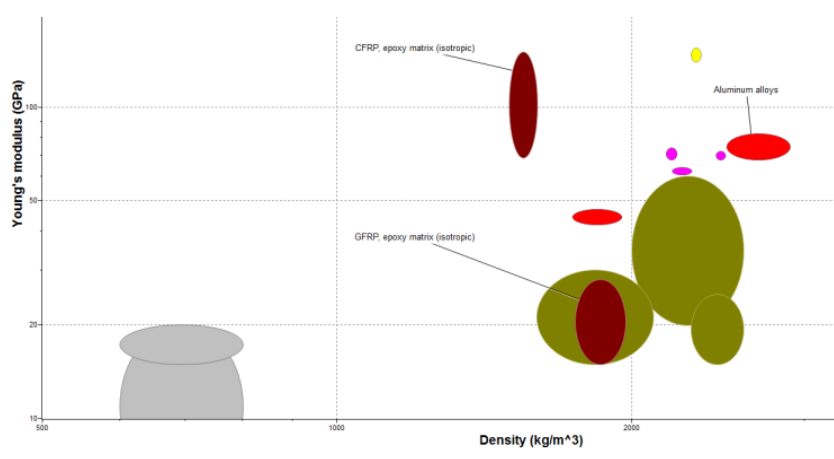

Fig.5. Comparison of composite and metals [4].

The selection of materials in case of wind turbine blades is best suited to composites such as carbon fiber or glass fibers and aluminium. Aluminium does not involve in today manufacturing of wind turbine blades due to their weight. Composite wind blades are molded in two halves and then glued together with an epoxy adhesive

Table 3. Material Properties and Specifications [4].

\begin{tabular}{|c|c|c|c|}
\hline Materials & Aluminum & Carbon Fiber & Glass fiber \\
\hline Density $\left(\mathrm{kg} / \mathrm{m}^{3}\right)$ & $2500-2900$ & $1500-1600$ & $1750-1970$ \\
\hline $\begin{array}{c}\text { Young's Modulus } \\
(\mathrm{GPa})\end{array}$ & $68-82$ & $69-150$ & $15-28$ \\
\hline $\begin{array}{c}\text { Tensile Strength } \\
(\mathrm{MPa})\end{array}$ & $58-550$ & $550-1050$ & $138-241$ \\
\hline Yield Strength (MPa) & $30-500$ & $550-1050$ & $110-192$ \\
\hline $\begin{array}{c}\text { Fatigue strength at } 10^{7} \\
\text { cycles (MPa) }\end{array}$ & $21.6-157$ & $150-300$ & $55-96$ \\
\hline $\begin{array}{c}\text { Max Service } \\
\text { temperature }\left({ }^{\circ} \mathrm{C}\right)\end{array}$ & $120-210$ & $140-220$ & $140-220$ \\
\hline $\begin{array}{c}\text { Thermal conductivity } \\
\left(\mathrm{W} / \mathrm{m}^{\circ} \mathrm{C}\right)\end{array}$ & $76-235$ & $1.28-2.6$ & $0.4-0.55$ \\
\hline $\begin{array}{c}\text { Specific heat capacity } \\
\left(\mathrm{J} / \mathrm{kg}^{\circ} \mathrm{C}\right)\end{array}$ & $857-990$ & $902-1004$ & $1000-1200$ \\
\hline \multicolumn{2}{|c|}{}
\end{tabular}

\section{Icing effects on the aerodynamics of wind turbine blades}

A significant degradation in the aerodynamic performance of wind turbine system occur by ice accretion on the surface of blades operated in cold climate. There is a need to improve knowledge about aerodynamic design and performance of wind turbine 
rotors for optimal and cost effective operations in icing conditions. The icing conditions within cold climates are insufficiently included in the design limits presently covered by national and international standards for wind turbine design. Atmospheric ice accretion on the wind turbine blades is caused by the impingement of super cooled water droplets. Most of these super cooled water droplets freeze immediately upon impact due to rapid heat dissipation leading to ice accretion. The parameters causing aerodynamic penalty can be divided into three categories: small-scale surface roughness, large-scale surface roughness and ice geometry [1].

Study of ice accretion on wind turbines aerodynamics have been carried out using analytical, numerical and experimental techniques. Experimental investigations of this subject have been performed using either an ordinary wind tunnel with artificial ice templates attached to the blade profile, or an icing wind tunnel. For the last decade or so Computational Fluid Dynamics (CFD) based numerical techniques have also begun to play a significant role in simulating the ice accretion on structures. The location of ice accretion and intensity of water impingement can be numerically determined by solving the air-water multiphase flow in the proximity of the wind turbine blade. Computational Fluid Dynamics (CFD) simulations are utilized to simulate the ice accretion process on a rotating wind turbine blade. Increase in the rotational speed leads to an increased ice thickness.

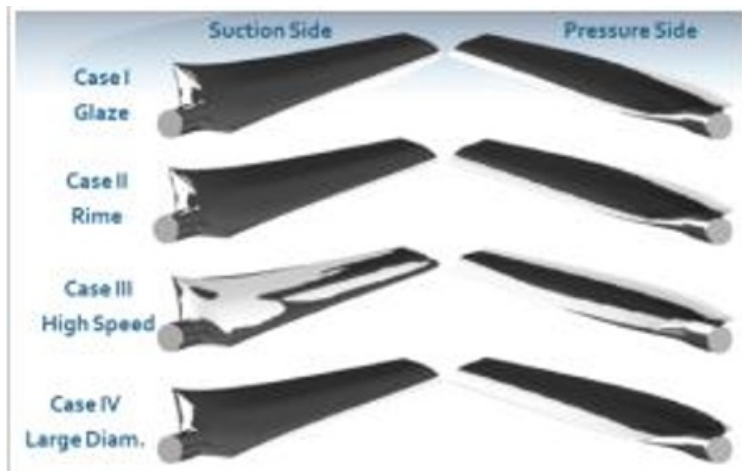

Fig.6. Ice coverage on wind tubrine blade in different icing conditions [5].

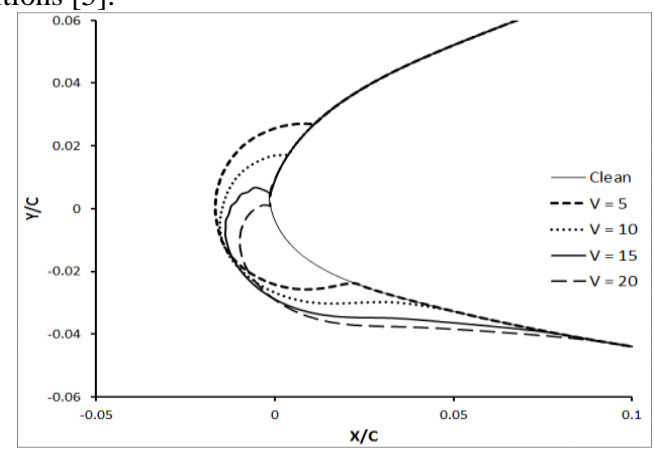

Fig.7.Effect of air velocity on ice shape [6].

Figure 8 describes the power coefficient in case of iced and clean blades. The CFD analysis shows that the iced blade have lower power output as compared to clean blade. In order to increase the power capacity of the wind turbine its size has to be increased also. In the same time, one has to optimize the design with respect to the weight of other components to ensure that cost effective energy conversion is maintained.

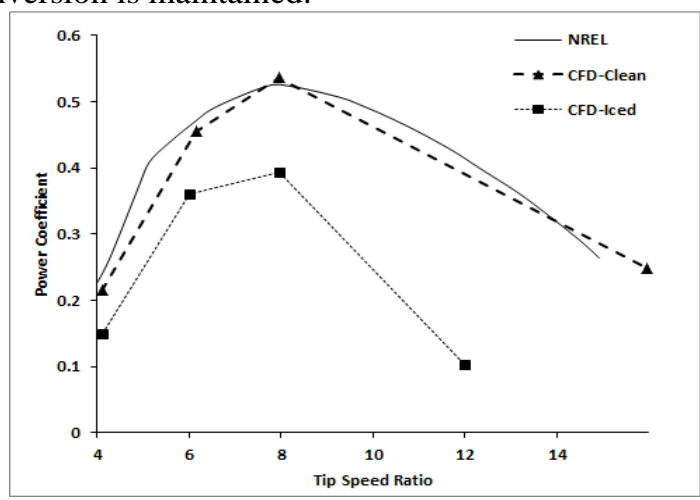

Fig.8.Power coefficient versus blade tip speed ration in case of clean and iced blade [6]

\section{Ice shedding of wind turbine blades}

The fall of accreted ice from a structure due to forces or change in temperature is called ice shedding. It is one of the operational challenges when it comes to cold climate where wind turbines are installed. The ice shedding depends on certain parameters such as weather conditions, turbine dimensions, rotational speed etc. This process is extremely dangerous for the personnel and the structure surrounding the wind turbine. Icing usually happens on moving blades. If we take any structure there are certain risk and safety factors that we have to consider. For wind turbines it can be ice accumulation, certain atmospheric conditions such as ambient temperatures near freezing point $\left(0^{\circ} \mathrm{C}\right)$ combined with high relative humidity, freezing rain or sleet. This kind of weather conditions allow ice to shed which can be hazardous for the surroundings. Safety concerns must be considered during the project development and operation.

\subsection{The risk involved in ice shedding}

The ice accretion on wind turbine blades is highly dependent on local weather conditions and the turbines operational state. It effects the geometry of the blades. Any ice that is accumulated on the blade may start to shed due to both gravity and the mechanical forces of the rotating blades. With the increase in ambient temperature, wind or solar radiation may cause sheets or fragments of ice loose and to fall. The rotation of wind turbine blades may propel ice fragments some distance from the turbine up to several hundred meters if the conditions are right. Falling ice can cause damage to structures and the public until or unless adequate measures are put in place for protection [7].

\subsection{Safety and operation of wind turbines}

The risk of ice throw must be taken into account during project planning and wind farm operation. We have to consider some of the factors that are based on industry 
practices when siting turbines to mitigate risk for iceprone project location. Turbine siting must be considered before installing the whole system. There must be safe distance from the occupied structure, road or public area. Wind energy production in cold climate provides the following formula for calculating a safe distance

$$
1.5 \times(\text { hub height }+ \text { rotor diameter })
$$

It should be noted that actual distance depends upon several parameters such as turbine dimension, its rotational speed etc.

Whenever site personnel detects ice accumulation, remotely switching off the wind turbine is the best option. There are several scenarios that can lead to an automatic shutdown of the turbine namely, detection of ice by a nacelle-mounted ice sensor or a shaft vibration sensor, and anemometer icing that leads to a measured wind speed below cut-in velocity of the turbine.

\subsection{Operator safety}

Access to turbines for site personnel should be restricted while ice remains on the structure. If site personnel need an access to wind turbine while ice is still present, safety precautions must be considered such as remotely shutting down the turbine, yawing to place the rotor on the opposite side of the tower door, parking vehicles at a distance of at least $100 \mathrm{~m}$ from the tower, and standard protective gear should be worn. If site personnel wants to restart the wind turbine blade it should be done remotely when work is complete [7].

\section{Conclusion}

Atmospheric icing presents a serious challenge to the wind energy industry in cold regions in terms of its safe operation and the energy harvest of the wind turbine.
Suitable material for wind turbine blades must be selected in terms of its go od resistance to corrosion and have the ability of high strength and hardness. During ice shedding risk must not be taken by keeping the wind turbine on. The phenomenon of ice shedding is associated with mechanical failure of ice. To prevent this process of ice shedding different designs of wind turbine blades should be develop and have practical experiment to evaluate the icing effect on the efficiency of the wind turbine.

The work reported in this research paper funded by the WindCoE (Nordic Wind Energy Centre) project funded within Interreg IVA Botnia-Atlantica, as part of European Territorial Cooperation (ETC).

\section{References}

1. Effect of atmospheric ice accretion on the dynamic performance of wind tubrine blades by Abdel Salam Alsabagh

2. Review of the Phenomenon of Ice Shedding from Wind Turbine Blades by H.Xue,H.Khawaja

3. Influence of Icing on the Modal Behavior of Wind Turbine Blades by Sudhakar Gantasala , Jean-Claude Luneno and Jan-Olov Aidanpää

4. CES EDUPACK

5. http://www.enginsoft.it/applications/aerospace/wind. html

6. Atmospheric icing effects on aerodynamics of wind turbine blade by R.S. Myong

7. Ice shedding and ice throw risk and mitigation by David Wahl and Phiippe Giguere. 